\title{
Chlorhexidine for umbilical cord care of the newborn: summary of evidence and its application in Sri Lanka
}

\author{
Hemali Jayakody ${ }^{1}$ \& Chrishantha Abeysena $^{2}$ \\ ${ }^{1}$ Ministry of Health, Sri Lanka; ${ }^{2}$ Department of Public Health, Faculty of Medicine, University of Kelaniya, \\ Sri Lanka \\ *Correspondence: gayathri_hj@yahoo.com (DD https://orcid.org/0000-0002-0444-2530
}

DOI: https://doi.org/10.4038/jccpsl.v25i3.8207

Received on: 11 May 2019

Accepted on: 29 July 2019

\section{Introduction}

\section{Chlorhexidine in umbilical cord care}

Umbilical cord is considered the most sensitive area in the newborn skin for bacterial colonization (1). Newborn umbilical cord infection (omphalitis) is polymicrobial in origin but predominated by Staphylococcus aureus, group A Streptococcus, Escherichia coli, Klebsiella pneumoniae and Proteus mirabilis (2). It is one of the leading causes for neonatal sepsis in the developing world. Omphalitis leads to necrotizing fasciitis, myonecrosis and systemic disease (2). Main risk factors for the umbilical cord infection are unhygienic delivery and wrong cord care practices especially at the community setting (3).

\section{Role of chlorhexidine}

Chlorhexidine is a broad-spectrum anti-microbial and an anti-septic agent. It inhibits spore growth of gram-positive bacteria; bacteriostatic against mycobacteria and inactivates lipid enveloped viruses (1). Chlorhexidine is active in many forms, but for neonatal cord care, the recommended dosage is $4 \%$ chlorhexidine (chlorhexidine di-gluconate $7.1 \%$ in aqueous solution or gel) (4).

Application of chlorhexidine to the neonatal cord received much debate recently (5-6). The American
Academy of Paediatrics and World Health Organization recommend providing clean and dry cord care for newborns in hospitals in regions with low neonatal mortality (i.e. $<30$ per 1000 live births) $(4,7)$. The Sri Lankan newborn care guideline published in 2014 states that umbilical cord should be kept dry and clean (8). However, a recent systematic review concluded that the use of chlorhexidine in cord care in hospital setting and community would reduce the morbidity and mortality of the newborn (9). Thus, this difference in the currently recommended practice in Sri Lanka and the emergence of new evidence synthesis queries whether there is a need to revise the current practice. On the other hand, Cochrane collaboration generates evidence using standardized protocols and influences local practitioners. Thus, we aimed to critically review the evidence synthesis on newborn cord care and implications of this evidence the local practice and recommendations.

\section{Briefly on the Cochrane review}

Sinha \& team reviewed the practices on chlorhexidine use pertaining to neonates in 2015. The review included 12 randomized controlled trials on application of chlorhexidine to neonatal cord, skin and as a maternal vaginal wash for hospital- and community-born children. The outcome was neonatal mortality and morbidity (10). 


\section{Box 1: Summary of the evidence collated in Cochrane Review}

Types of studies There were four cluster-randomized community trials and eight randomized controlled trials included in the review.

Study settings Two of the 12 studies were from European countries, and the remainder from South Asian (7) and African countries.

Participants Four studies included pregnant women and eight studies recruited neonates. Neonates were recruited at the time of birth or within first 36 hours of life. Community-based studies recruited neonates who were delivered at home or pregnant mothers who wanted to deliver at home. Traditional birth attendants delivered the baby as well as the intervention at the community.

Interventions

The review had six interventions on application of chlorhexidine. Chlorhexidine was applied to the neonatal skin and/or to the umbilical cord stump and to the maternal vagina at the time of childbirth. The procedure was done at the community or/and hospital setting. The strength and preparation of chlorhexidine varied across studies. The concentration ranged from $0.25 \%$ to $4 \%$ chlorhexidine solution. Excluding one study, all others looked at multiple applications of chlorhexidine to neonatal skin or cord across days and weeks.

Outcomes Neonatal mortality, infection and omphalitis were the outcomes studied in both hospital- and community-based studies. In the trials which included maternal vaginal wash as an intervention, neonatal hypothermia was considered as a secondary outcome.

Source: Sinha, Sinha A, Sazawal S, Pradhan A, Ramji S, Opiyo N. Chlorhexidine skin or cord care for prevention of mortality and infections in neonates. Cochrane Database of Systematic Reviews 2015, Issue 3. Art. No.: CD007835. DOI: 10.1002/ 14651858.CD007835.pub2.

Table 1 provides a summary of the key findings of the review. Application of chlorhexidine to the neonatal skin or cord did not reduce mortality for hospital births. Evidence was moderate or low for reducing morbidity of newborns when applied to skin or cord for the hospital births. However, there was high quality evidence to conclude that chlorhexidine can reduce mortality and morbidity among the neonates who are born in the community. Reviewers reported that the effectiveness of maternal vaginal wash at the time of childbirth could not be proved. 
Table 1. Results generated for the six interventions in the Cochrane review and their respective outcomes

\begin{tabular}{|c|c|c|c|c|c|c|c|}
\hline \multirow[b]{2}{*}{ Intervention } & \multirow[b]{2}{*}{ Outcome } & \multicolumn{2}{|c|}{ Risk } & \multirow[b]{2}{*}{$\begin{array}{c}\text { Relative risk } \\
(95 \% \text { CI })\end{array}$} & \multirow[b]{2}{*}{$\begin{array}{l}\text { No. } \\
\text { trials }\end{array}$} & \multirow[b]{2}{*}{ Sample } & \multirow{2}{*}{$\begin{array}{l}\text { Overall } \\
\text { evidence } \\
\text { quality }\end{array}$} \\
\hline & & $\begin{array}{l}\text { Control } \\
\text { group }\end{array}$ & $\begin{array}{c}\text { Intervention } \\
\text { group }\end{array}$ & & & & \\
\hline \multirow{2}{*}{$\begin{array}{l}\text { Chlorhexidine to } \\
\text { the neonatal } \\
\text { umbilical cord at } \\
\text { the hospital setting }\end{array}$} & Mortality & $57: 1000$ & $6: 1000$ & $\begin{array}{c}0.11 \\
(0.01-2.04) \\
\end{array}$ & 1 & 140 & Low \\
\hline & Morbidity & $77: 1000$ & $37: 1000$ & $\begin{array}{c}0.48 \\
(0.28-0.84)\end{array}$ & 2 & 809 & Moderate \\
\hline \multirow{2}{*}{$\begin{array}{l}\text { Chlorhexidine for } \\
\text { neonatal skin } \\
\text { cleansing at the } \\
\text { hospital setting }\end{array}$} & Morbidity & $\begin{array}{c}\text { Not } \\
\text { calculated }\end{array}$ & & & & & $\begin{array}{l}\text { No study } \\
\text { reported }\end{array}$ \\
\hline & Morbidity & 118:1000 & 104:1000 & $\begin{array}{c}0.88 \\
(0.56-1.39)\end{array}$ & 2 & 642 & Low \\
\hline \multirow{2}{*}{$\begin{array}{l}\text { Chlorhexidine for } \\
\text { neonatal cord care } \\
\text { at the community } \\
\text { setting }\end{array}$} & Mortality & $51: 1000$ & $41: 1000$ & $\begin{array}{c}0.81 \\
(0.71-0.92)\end{array}$ & 3 & 31084 & High \\
\hline & Morbidity & $20: 1000$ & $10: 1000$ & $\begin{array}{c}0.48 \\
(0.4-0.57)\end{array}$ & 3 & 39925 & High \\
\hline \multirow{2}{*}{$\begin{array}{l}\text { Chlorhexidine for } \\
\text { neonatal skin } \\
\text { cleansing at the } \\
\text { community setting }\end{array}$} & Mortality & $30: 1000$ & $31: 1000$ & $\begin{array}{c}1.03 \\
(0.87-1.23)\end{array}$ & 1 & 17530 & High \\
\hline & Morbidity & - & & & & & - \\
\hline \multirow{2}{*}{$\begin{array}{l}\text { Maternal vaginal } \\
\text { wash with neonatal } \\
\text { skin cleansing at } \\
\text { the hospital }\end{array}$} & Mortality & $23: 1000$ & $22: 1000$ & $\begin{array}{c}0.98 \\
(0.67-1.42)\end{array}$ & 1 & 4904 & Moderate \\
\hline & Morbidity & 39:1000 & $38: 1000$ & $\begin{array}{c}0.98 \\
(0.82-1.16)\end{array}$ & 2 & 13033 & High \\
\hline \multirow{2}{*}{$\begin{array}{l}\text { Maternal vaginal } \\
\text { wash with neonatal } \\
\text { skin cleansing at } \\
\text { the community }\end{array}$} & Mortality & $2: 100$ & $0: 100$ & $\begin{array}{c}0.2 \\
(0.01-4.03)\end{array}$ & 1 & 202 & Low \\
\hline & Morbidity & 510: 1000 & $352: 1000$ & $\begin{array}{c}0.69 \\
(0.49-0.95)\end{array}$ & 1 & 203 & Moderate \\
\hline
\end{tabular}

\section{Application of the findings to Sri Lanka}

Though there were six interventions reviewed in Cochrane, only one is useful to Sri Lanka. Three interventions were assessed pertaining to hospital and community births. In Sri Lanka, 99.9\% births occur in hospitals, so we reviewed only the interventions for hospital births (11). We excluded the intervention on maternal vaginal wash with chlorhexidine due to its ineffectiveness. None of the other two interventions application of chlorhexidine to neonatal skin or cordreduced the mortality, but there was low-moderate quality evidence that they reduce neonatal morbidity. As shown in Table 1, neonatal skin cleansing at the hospital setting did not show a statistically significant 
relative effect. After excluding five interventions (due to lack of effectiveness or non-applicability to Sri Lanka), we reviewed the appropriateness of application of chlorhexidine for the neonatal cord at the hospital setting in Sri Lanka in terms of applicability, impact, feasibility and acceptability.

\section{Application of chlorhexidine for umbilical cord care in the hospital setting}

For the pooled analysis on cord cleansing with chlorhexidine, two studies were considered. The study by Gathwala and team was conducted among 140 newborns cared at neonatal intensive care units in tertiary care hospitals in India in 2013 (12). The exact intervention was chlorhexidine gluconate solution $2.5 \%$ was applied on the neonatal cord and the control group received dry cord care. Kapellen investigated the intervention among 669 newborns from neonatal care units in Germany. They applied chlorhexidine powder to the umbilical cord and the control group received dry cord care (13).

\section{Box 2. Appropriateness of chlorhexidine for neonatal cord care at the hospital setting in Sri Lanka}

\section{Applicability}

Cochrane review was in good quality according to AMSTAR criteria (14). However, the reviewers had not assessed publication bias due to the limited number of studies.

The generalizability of the findings to Sri Lankan setting is limited. Strength and the method of application of chlorhexidine in the two studies were different (Gathwala et al used 2.5\% chlorhexidine solution and Kapellen et al used chlorhexidine powder). We cannot arrive at a conclusion on the possible mode of application of chlorhexidine. However, in both studies the control group received dry cord care which is the existing practice in Sri Lanka. Thus, it is necessary to downgrade the evidence due to the indirectness (15).

\section{Impact}

In 2014, 2165 neonatal deaths were reported in Sri Lanka. Of them ,194 were attributed to neonatal sepsis (11). We do not have evidence on the incidence of omphalitis since the introduction of dry cord care. Thus, impact of the intervention could not be measured or will be minimal.

\section{Feasibility}

Application of chlorhexidine to the neonatal cord is a low-cost intervention. The coverage of recommended interventions at the immediate postnatal care at the hospital is satisfactory in Sri Lanka (16). Thus, it would be feasible to introduce a new intervention to the existing package. However, the staff needs to be trained adequate; it will incur a cost.

\section{Acceptability}

The intervention should be acceptable to both parents and health care providers. Application of a 'liquid' to the neonatal umbilical cord was a routine practice in Sri Lanka some time back (before the introduction of dry cord care) (17). Reverting back to the previous practice will not be impossible for parents. If health care providers are trained on the new practice and the guideline made available on application of chlorhexidine to neonatal cord care, acceptability among the health staff would be high. 


\section{Implication for practice and research}

The evidence on application of chlorhexidine in newborn cord at the hospital was low-moderate according to the Cochrane review. The applicability of evidence will be low in the local setting. Feasibility and acceptability of the practice will be good within the existing health infrastructure. The impact made by the new intervention could not be assessed, without information on the burden of neonatal sepsis or omphalitis in the general newborn population. We conclude that the intervention recommended in Cochrane review by Sinha et al is not required for Sri Lanka.

Unavailability of good evidence is a major drawback with regard to this practice. Therefore, we suggest a local study on the effectiveness chlorhexidine in umbilical cord care among newborns. It also needs to be supplemented with a burden assessment of omphalitis and neonatal sepsis with the current practice on dry cord care.

\section{Author Declarations}

Conflicts of interest: Authors declare no conflicts of interests.

Acknowledgement: The authors wish to acknowledge the technical support received from Professor Prathap Tharyan and Professor Paul Garner.

\section{References}

1. Ortegón L, Puentes-Herrera M, Corrales IF, Cortés JA. Colonization and infection in the newborn infant: Does chlorhexidine play a role in infection prevention? Archivos Argentinos de Pediatría 2017; 115(1): 5.

2. Gallagher PG, Shah SS, Windle ML, Carter BS. Omphalitis, 2016 [01/08/2017]. Available from: http:// emedicine.medscape.com/article/975422-overview.

3. Mullany LC, Darmstadt GL, Katz J, Khatry SK, LeClerq SC, Adhikari RK, et al. Risk factors for umbilical cord infection among newborns of Southern Nepal. American Journal of Epidemiology 2007; 165(2): 203-211.

4. WHO. WHO Recommendations on Postnatal Care of Mother and Newborn. Geneva: World Health Organization, 2013.
5. Osrin D \& Colbourn T. No reason to change WHO Guidelines on Cleansing the Umbilical Cord. Lancet Global Health 2016; 4(11): e766-e8.

6. Hodgins S. Chlorhexidine and newborn omphalitis and mortality. Lancet Global Health 2017; 5(3): e270-e1.

7. American Academy of Pediatrics; American College of Obstetricians and Gynecologists. Guidelines for Perinatal Care. In Riley LE \& Stark AR(Eds.), 2012.

8. Family Health Bureau. National Guidelines for Newborn Care Ministry of Health. Colombo: Ministry of Health, 2014.

9. Sankar MJ, Chandrasekaran A, Ravindranath A, Agarwal R. Umbilical cord cleansing with chlorhexidine in neonates: a systematic review. Journal of Perinatology 2016; 36 Suppl 1: S12-20.

10. Sinha A, Sazawal S, Pradhan A, Ramji S, Opiyo N. Chlorhexidine skin or cord care for prevention of mortality and infections in neonates. Cochrane Database of Systematic Reviews 2015(3).

11. Family Health Bureau. Annual Report of Family Health. Colombo: Ministry of Health, 2014.

12. Gathwala G, Sharma D, Bhakhri B. Effect of topical application of chlorhexidine for umbilical cord care in comparison with conventional dry cord care on the risk of neonatal sepsis: a randomized controlled trial. Journal of Tropical Pediatrics 2013; 59(3): 209-213.

13. Kapellen TM, Gebauer CM, Brosteanu O, Labitzke B, Vogtmann C, Kiess W. Higher rate of cord-related adverse events in neonates with dry umbilical cord care compared to chlorhexidine powder. Results of a randomized controlled study to compare efficacy and safety of chlorhexidine powder versus dry care in umbilical cord care of the newborn. Neonatology 2009; 96(1): 13-18.

14. Shea BJ, Grimshaw JM, Wells GA, Boers M, Andersson N, Hamel C, et al. Development of AMSTAR: a measurement tool to assess the methodological quality of systematic reviews. BMC Medical Research Methodology 2007; 7(1): 10.

15. Guyatt GH, Oxman AD, Kunz R, Vist GE, Falck-YtterY, Schunemann HJ. What is "quality of evidence" and why is it important to clinicians? BMJ 2008; 336(7651): 995-998.

16. Family Health Bureau. National Obstetrics and Neonatal Emergency Care Needs Assessment: Country Report. Colombo: Ministry of Helath, 2012.

17. Senarath U, Fernando DN, Rodrigo I. Newborn care practices at home: effect of a hospital-based intervention in Sri Lanka. Journal of Tropical Pediatrics 2006; 53(2). 